\title{
Análise da configuração espacial de escolas públicas, estudos de casos de ambientes escolares de Maceió, Alagoas
}

\author{
Spatial configuration analysis of public schools, case studies of \\ Maceió, Alagoas schools' environments
}

THAISA SAMPAIO SARMENTO Arquiteta e Urbanista, Mestre em Arquitetura e Urbanismo, Doutora em Design, Universidade Federal de Alagoas, e-mail: thaisa.sampaio@fau.ufal.br

GABRIELLA LIRA CANUTO

Graduanda em Arquitetura e Urbanismo, Universidade Federal de Alagoas, e-mail: gabriellacanuto@gmail.com

\section{RESUMO}

Ao longo da história, a educação e seu ambiente físico principal, a escola, passaram por diversas transformações. O modelo espacial da escola da atualidade é advindo do período da Revolução Industrial, de uma educação em série para seguir o modelo de produção fabril. A configuração espacial da escola influencia o comportamento e o bem-estar dos estudantes, impactando também no rendimento escolar. Um espaço escolar adequado às necessidades dos usuários, pode contribuir para um rendimento escolar mais satisfatório. Este artigo propõe-se a analisar a configuração espacial de escolas públicas em Maceió, Alagoas, a fim de identificar padrões projetuais, de uso e ocupação dos ambientes de aprendizagem e convivência. A metodologia utilizada é baseada em revisão de literatura sobre história dos ambientes de educação, arquitetura escolar e condições de desempenho ambiental e ergonômico para escolas. Os resultados apresentados foram organizados em mapas e tabelas, a fim de compor uma caracterização espacial global, para ambientes escolares da cidade de Maceió, Alagoas.

PALAVRAS-CHAVE: arquitetura escolar, análise espacial, padrões projetuais.

\section{ABSTRACT}

Education and its school environment were under several transformations throughout history. The spatial model of actual school is from Industrial Revolution period, aimed to form people as a manufacturing production model. The spatial configuration of the school influences the behavior and well-being of students, also impacting on their school performance. An appropriate school 


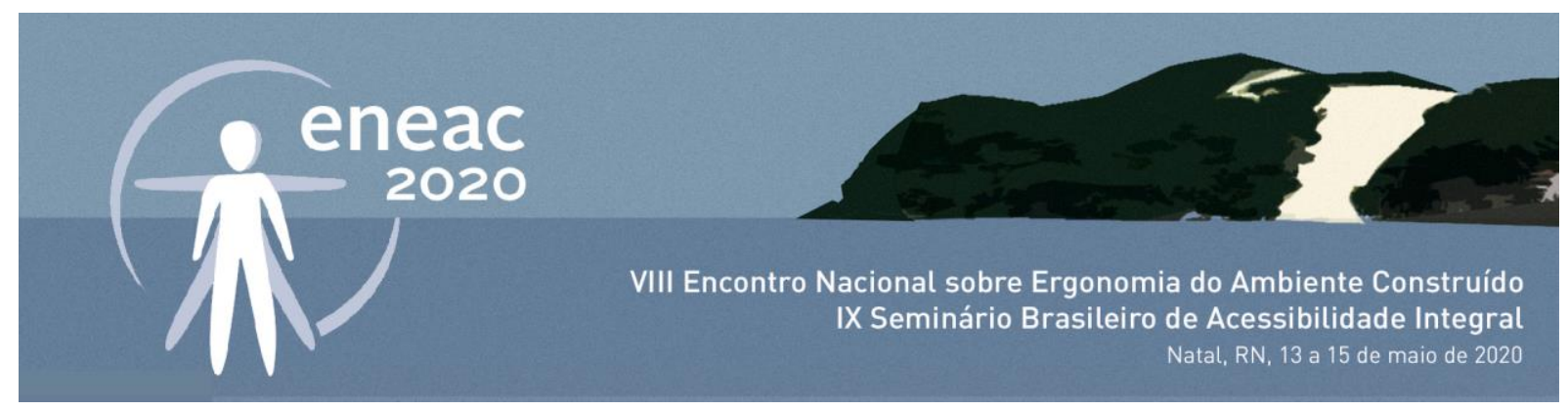

environment can contribute to a more satisfactory students' performance. This article aims to analyze the spatial configuration of public schools in Maceió, Alagoas, in order to identify project current patterns, forms of using and occupation of learning and coexistence environments. The methodology used is based on a literature review about education history, school architecture and environmental and ergonomic performance conditions for schools. Presented results were organized in maps and tables, in order to compose a global spatial characterization, for school environments in the city of Maceió, Alagoas.

KEYWORDS: school architecture, spatial analysis, design patterns.

\section{INTRODUÇÃO}

O ambiente exerce influência nos estudantes, causando sensações positivas e, às vezes, negativas. Essas implicações são diferentes de pessoa para pessoa, mesmo assim percebe-se que há influência da qualidade do ambiente nas interações sociais que ocorrem no grupo ao qual pertencem (KAUP; KIM; DUDEK, 2013; CHAN; RICHARDSON, 2005).

É fundamental considerar a importância do papel exercido pelo espaço físico e pelo clima social proporcionado pela escola no desempenho dos estudantes. Além dos métodos e formas de aprendizagem, o espaço físico da escola também interfere na capacidade de concentração e nas questões de identidade e relacionamento com os pares. Uma escola com espaço físico agradável, amplo, em conexão com a natureza, e com clima social positivo pode apresentar um rendimento escolar mais satisfatório e índices de avaliação melhores.

Nesse sentido, este artigo objetiva realizar uma análise da configuração espacial de escolas públicas em Maceió, Alagoas, a fim de identificar padrões projetuais, de uso e ocupação dos ambientes de aprendizagem e convivência. Foram observados aspectos de dimensionamento, ergonomia, circulação e acessibilidade no interior dessas edificações. Para a elaboração deste artigo, foram utilizados dados obtidos com o Projeto PIBIC 2019-2020 - Análise de Ambientes Educacionais de Escolas Públicas de Alagoas - Considerações sobre aspectos sociais, culturais e ambientais. As escolas objeto deste estudo são todas localizadas na cidade de Maceió, Alagoas: Escola Estadual Moreira e Silva (EEMS), Escola Estadual Princesa Isabel (EEPI) e Centro Municipal de Educação Infantil (Cmei) Professora Fúlvia Maria De Barros Mott Rosemberg. As duas escolas estaduais estão localizadas no Centro Educacional De Pesquisa Aplicada (CEPA), no bairro do Farol, na Av. Fernandes Lima. A Cmei está locada no bairro Village Campestre, na Av. Alice Carolina. O CEPA (Centro Educacional De Pesquisa Aplicada) é complexo alagoano de escolas, esse completa 62 anos de existência, com 11 escolas internas e 7.827 alunos é um dos maiores na América Latina. As escolas estaduais atendem ao público jovem, na faixa etária de 15 a 17 anos e a escola municipal Cmei atende ao público entre 0 a 5 anos.

\section{MÉTODO DE PESQUISA}

A metodologia utilizada foi embasada na revisão de literatura existente sobre arquitetura escolar, história dos ambientes de educação e design de ambientes de aprendizagem, segundo Aranha 


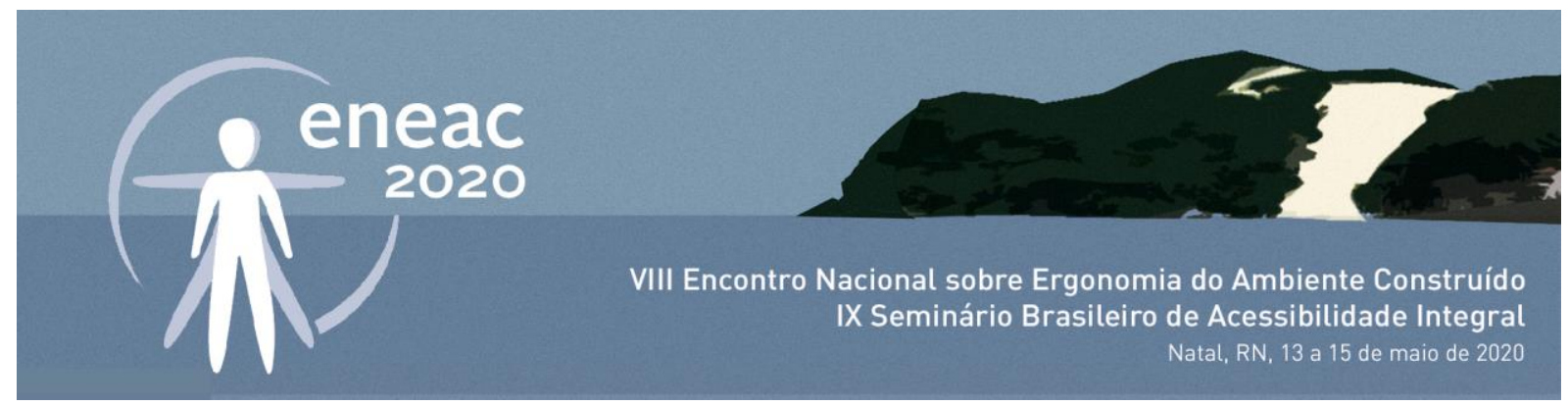

(1996), Moran (2014), Sarmento e Gomes (2019), entre outros. A coleta de dados nas escolas dedicou-se a gerar dados dimensionais, fotográficos, anotações e registros das formas de utilização dos ambientes, da configuração formal e espacial da edificação escolar e da observação dos usuários no ambiente em uso. Para análise dos ambientes, as pesquisadoras observaram os usuários desenvolvendo atividades nos horários onde as aulas aconteciam e em atividades esportivas. As visitas para coleta de dados ocorreram no período de dezembro de 2019 , durante o período de verão, no qual é recomendado utilizar espaços abertos e amplos, com melhor ventilação natural, para amenizar a sensação de calor.

As etapas metodológicas da pesquisa foram assim definidas:

- Aprofundamento teórico - leitura de livros, artigos e dissertações para elaboração da revisão de literatura e escolha das ferramentas de análise;

- Coleta de dados in loco - Visitas exploratórias realizadas nas escolas objeto do estudo, para coleta de dados sobre dimensionamento, fluxos e permanência, e análise dos ambientes em uso e análise do desempenho ambiental global;

- Análise dos dados obtidos - os dados coletados foram sintetizados em tabelas e mapas, para fins de síntese geral e elaboração de diagnóstico.

Os condicionantes para análise física foram obtidos em recomendações normativas de desempenho conforto térmico, acústico, lumínico e dimensional, de acordo com as seguintes normativas e fontes: NBR 15220 (ABNT, 2003): Desempenho térmico de edificações - Parte 1, 2 e 3; NBR 8995-1 (ABNT, 2013); NBR 10152 (ABNT, DATA); e Catálogo de Ambiente Especificações da Edificação Escolar (FDE, 2017): Para análise das áreas internas úteis, dos ambientes escolares analisados.

\section{REVISÃO DE LITERATURA}

Historicamente, a arquitetura de escolas foi orientada a um modelo de ensino que visava mais o controle do que o desenvolvimento cognitivo das crianças. Além dos problemas de gestão e de condução da aprendizagem, Sarmento et al. (2020) discute que ainda hoje no Brasil, as condições físicas das escolas são insatisfatórias, considerando os dados do censo escolar 2017 (INSTITUTO..., 2018) sobre infraestrutura física das escolas de ensino fundamental no Brasil:

- Apenas $41,6 \%$ das escolas contam com rede de esgoto;

- O fornecimento de água, por rede pública, ocorre em $65,8 \%$ das escolas;

- Em 10 \% das escolas do país não há nenhum abastecimento de energia ou água;

- $46,8 \%$ das escolas de ensino fundamental dispõem de laboratório de informática, $65,6 \%$ das escolas têm acesso à internet; em 53,5\% das escolas a internet é por banda larga;

- Apenas $11,5 \%$ das escolas de ensino fundamental dispõem de laboratório de ciências, 53,5\% das escolas dispõem de biblioteca e/ou sala de leitura;

- Ter banheiro acessível é uma realidade em apenas 39,9\% das escolas, e em 9,2\% das escolas não existe banheiro; e

- Espaços de lazer e convivência foram observados nas seguintes proporções: 27,5\% das 


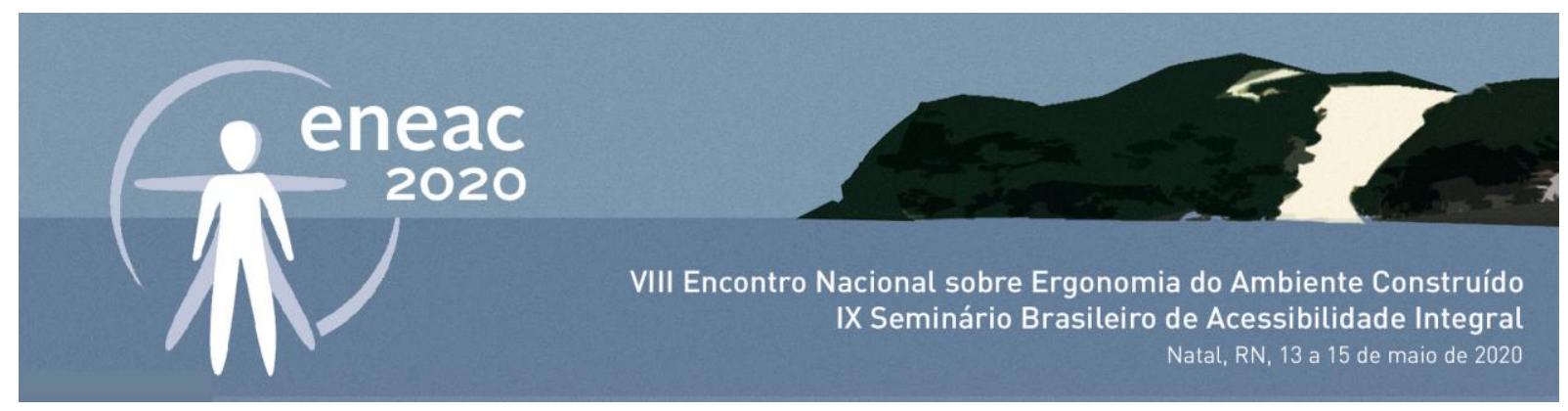

escolas fundamentais e infantis dispõem de parque infantil, $67,5 \%$ das escolas possuem pátio (coberto ou descoberto) e 41,2\% das escolas têm quadra de esportes.

Esses dados mostram que no Brasil há preocupação em prover condições mínimas de infraestrutura na rede pública de ensino, entretanto não há evidências da qualidade ou de padrões de conforto ou de eficiência dos ambientes de aprendizagem oferecidos (SARMENTO et al., 2020). Nos últimos 30 anos a configuração arquitetônica mais usada em edifícios escolares remete a um formato monolítico padronizado de até 3 pavimentos. Souza (2018) e Santiago (2017) demonstraram que a tipologia escolar segue uma organização espacial em pavimentos; organizadas em corredores lineares, as salas de aula são retangulares ou quadradas. Os formatos de corredores mais frequentes são em linha, em U ou em L.

No ensino tradicional, especialmente de escolas públicas, percebe-se que ocorrem inúmeras adaptações de uso dos ambientes escolares, reformas desconexas da configuração original, problemas de desconforto ambiental em muitos ambientes, condições de inadequação ergonômica do mobiliário, a má iluminação em mesas de trabalho. Quando há laboratórios de informática, o layout deste ambiente é sempre mal elaborado, os equipamentos são instalados de maneira improvisada, telas dos desktops mal posicionadas em relação à lousa e em relação às janelas, a pouca proteção das aberturas contra o ofuscamento, causado pela iluminação direta. Somam-se a esses problemas turmas muito numerosas e um único professor para conduzir a aprendizagem.

A configuração da arquitetura escolar de escolas públicas brasileiras não evoluiu tanto quanto seria necessário, para a educação com recursos digitais. A maioria das edificações escolares ganhou ambientes adaptados a novos usos, como é o caso do laboratório de informática, item corriqueiro nas escolas brasileiras atuais. No entanto, o acesso a recursos computacionais e à internet é, na maioria das escolas, restrito a esses laboratórios, e seu uso é controlado por professores.

O desempenho de fatores de conforto ambiental é observado não apenas em índices numéricos, mas por observação dos aspectos sociais e culturais. Um ambiente que contribui para o bem-estar dos alunos atende às necessidade de adequação climática, podendo transmitir sensações positivas e criar um significado para o ambiente. No Brasil, nota-se que são precariamente seguidas as condições mínimas de conforto ambiental em salas de aula, de acordo com Kowaltowski (2011), Guindalli e Bins Ely (2013), Bertolotti (2007), Alcântara (2011), que recomendam os seguintes critérios de desempenho:

- desempenho térmico proporcionado por sombreamento de aberturas (cortinas, persianas, brises externos, entorno e vegetação), uso de ventilação natural, cruzada ou mecânica (KOWALTOWSKI, 2011); seguir a NBR 15220 (ABNT, 2003) para obter sombreamento de aberturas respeitando as recomendações para as zonas bioclimáticas brasileiras: Zona 1 permitir entrada de sol no período frio, Zonas 2 e 3 - permitir entrada de sol no inverno, e Zonas 4 a 8 - sombrear aberturas durante todo o ano (GURGEL, 2012; ABNT, 2003);

- aplicar as recomendações mínimas de desempenho para cada aspecto de conforto ambiental - térmico (NBR 15220, ABNT, 2003), lumínico (ABNT, 2013) e acústico (ABNT, 1999), criando assim uma base mínima de níveis de conforto; e

- iluminação natural uniforme, indireta e refletida sobre o plano de trabalho, prevendo uma faixa contínua de janelas e prateleiras de luz (GUINDALLI; BINS ELY, 2013; BERTOLOTTI, 2007); 


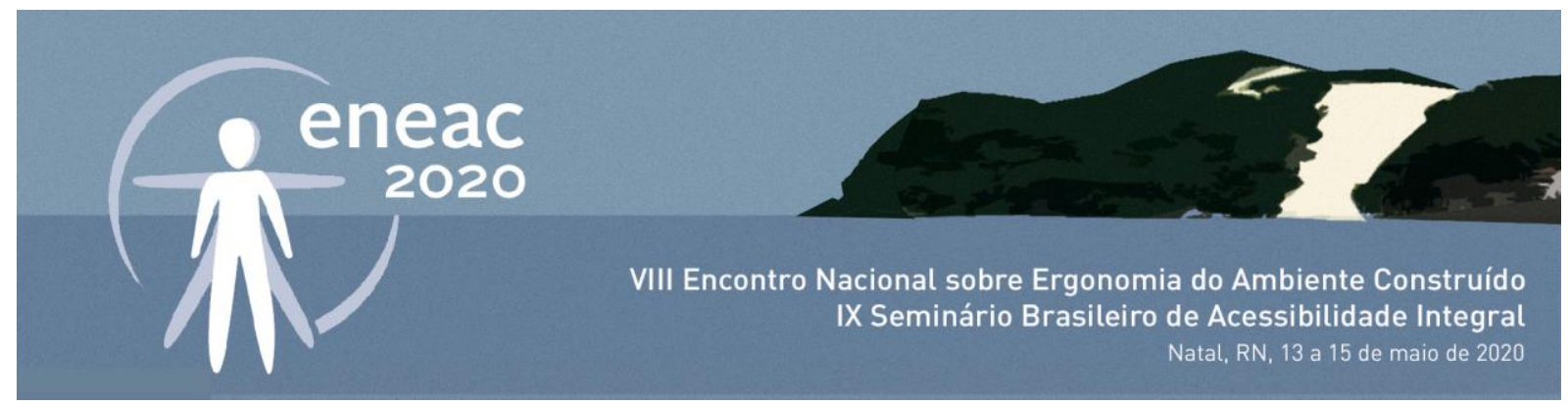

- boa condição acústica para a palavra falada, níveis baixos de ruído de fundo, não interferindo na inteligibilidade, salas livres de eco ou de fenômenos de distorção sonora, devendo propiciar o tempo de reverberação adequado para cada tipo de atividade (ALCÂNTARA, 2011).

O ideal para a qualidade térmica de salas de aula é uma boa orientação da forma da edificação, evitando o aquecimento das paredes de ambientes de permanência no período da tarde, durante a insolação poente. A orientação da edificação também determina o fluxo de ventilação natural. Em salas de aulas devem ser consideradas privilegiar a ventilação para esses espaços, como requisito de projeto arquitetônico (SCHMID, 2005).

A combinação das condições de iluminação natural e da orientação geográfica da edificação também implicam na incidência de iluminação dentro das salas de aula, sabendo-se que a incidência solar direta incomoda os usuários, causando ofuscamento. Estudo de cartas solares em relação ao projeto arquitetônico, e os elementos de proteção solar podem promover um melhor desempenho de proteção por meio de brises, cobogós e outros (LAMBERTS, 2014).

Em relação a qualidade acústica de uma sala de aula é importante manter o equilíbrio na reverberação, o isolamento acústico para evitar ruídos externos indesejados.

Em relação a condição da funcionalidade espacial, Deliberador (2010) considera que os espaços escolares determinam as formas de realização das atividades humanas ao nível de ensino. Os fluxos de usuários na edificação devem ser considerados como um dos parâmetros de conforto ergonômico, de acessibilidade e de funcionalidade do edifício. Isso inclui verificar detalhes como, por exemplo, o sentido de abertura de portas, a otimização de grandes fluxos para entrada e saída de ambientes como auditórios, salas de aula e ginásios de esportes, dimensionamento e layout de mobiliário e de equipamentos de apoio ao ensino. Deliberador (2010) e Kowaltowski et al. (2001) apontaram para aspectos mínimos a serem respeitados:

- A densidade populacional;

- A disponibilidade de ambientes para atividades variadas e específicas;

- A existência de locais de armazenamento e exposição de materiais didáticos;

- O relacionamento otimizado entre ambientes;

- A adequação do projeto ao usuário com dificuldade de locomoção.

Com base na breve descrição da revisão de literatura, pode-se executar as análises dos ambientes escolares, como detalhado no item 4, a seguir.

\section{ANÁLISE DE DADOS OBTIDOS}

\subsection{ESCOLA A - Centro Municipal de Educação Infantil (Cmei) - Professora Fúlvia Maria De Barros Mott Rosemberg:}

A escola foi fundada em 2015, e utiliza a pedagogia orgânica como método de ensino e aprendizagem. O pátio da escola é chamado de praça pela comunidade estudantil. É um local coberto e protegido, com algumas telhas translúcidas para que a luz natural posso entrar e evitar o uso de iluminação artificial. Desta forma é possível garantir iluminação adequada as atividades 


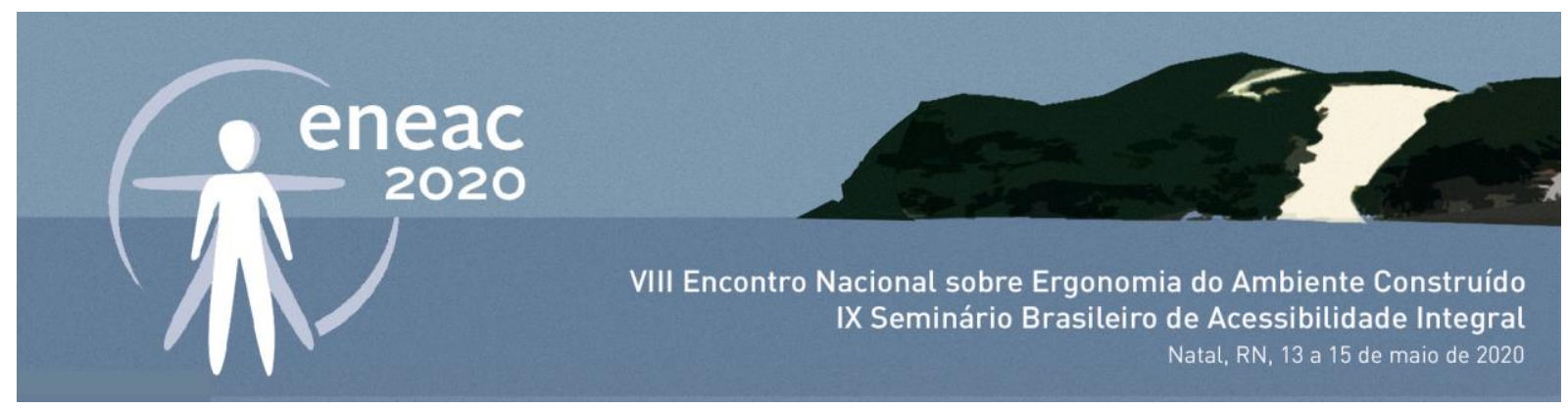

propostas na praça, essas são: refeições (já que o refeitório é na praça), brincadeiras educativas como: pular amarelinha e atividades artísticas, a depender da dinâmica da aula do dia. Durante a visita exploratória, as crianças trabalhavam no pátio, coletando material da natureza.

O projeto original da escola foi desenvolvido pelo Fundo Nacional de Desenvolvimento da Educação - FNDE, como modelo padrão para construções de escolas em todo o país, assim já é previsto a falta de adequação para o clima da cidade o que prejudica o conforto térmico.

Desse modo, as condições climáticas locais e o terreno não foram considerados para o projeto arquitetônico, e algumas inconformidades foram encontradas pois as adequações recomendadas pelo Manual Para Adequação De Prédios Escolares do Fundo Nacional de Desenvolvimento de Educação não foram realizadas, como arborização em locais estratégicos, utilização de quebra sol para proteção de aberturas isto não foi visto no processo de visitação da escola (FNDE ,2005).

Figura 1: Espaço externo da praça (a) e condição interna da praça (b).
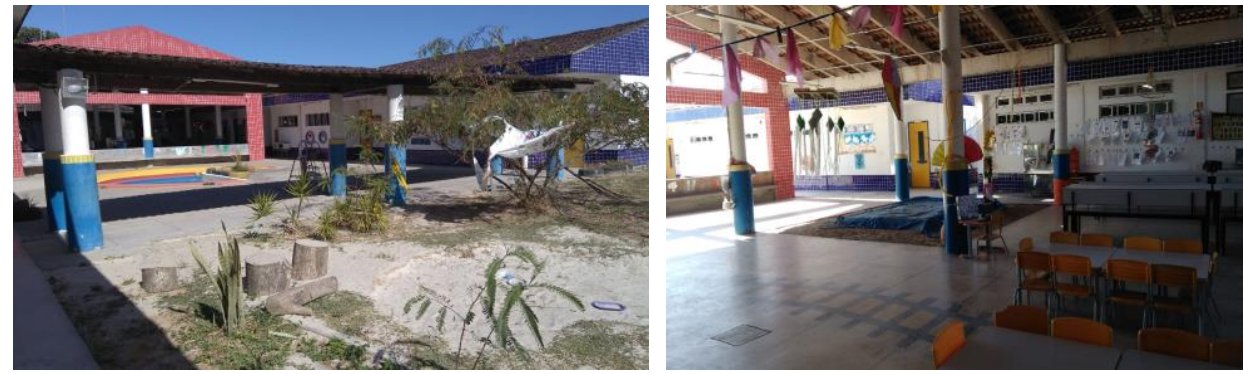

Fonte: As autoras.

Figura 2: Planta de setorização ESCOLA A.

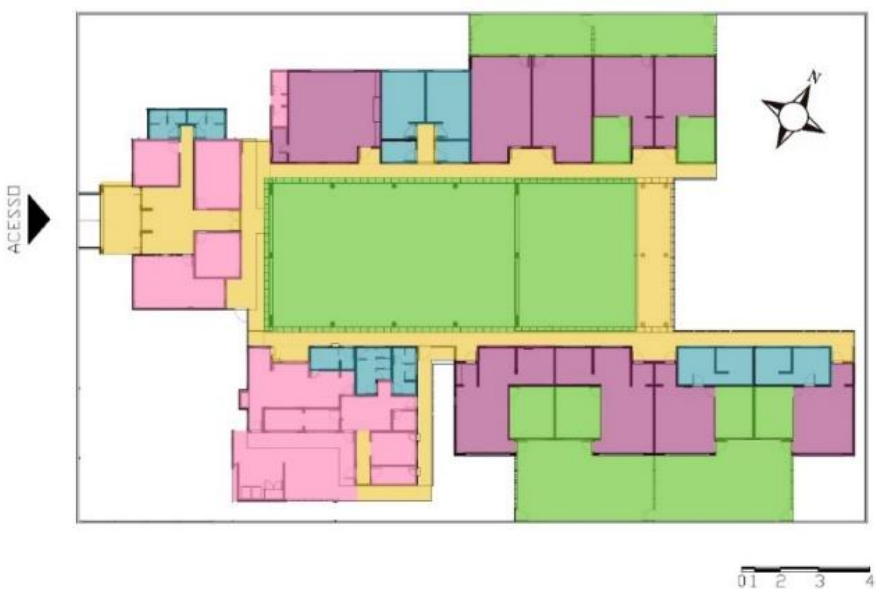

Sala de aula

Laboratórios (bibliotecas, informáticas, refeitório, etc)

Espaço administrativo

Banheiro

Circulaçâo

Espaço de convivência/repouso

Fonte: Adaptado do projeto PROINFANCIA B, FNDE.

Os espaços de permanência da escola deveriam ser projetados para considerar as condições favoráveis de ventilação e iluminação naturais, porém pela implantação de um projeto-padrão, não foi priorizado orientar salas de aula sempre na posição favorável. 


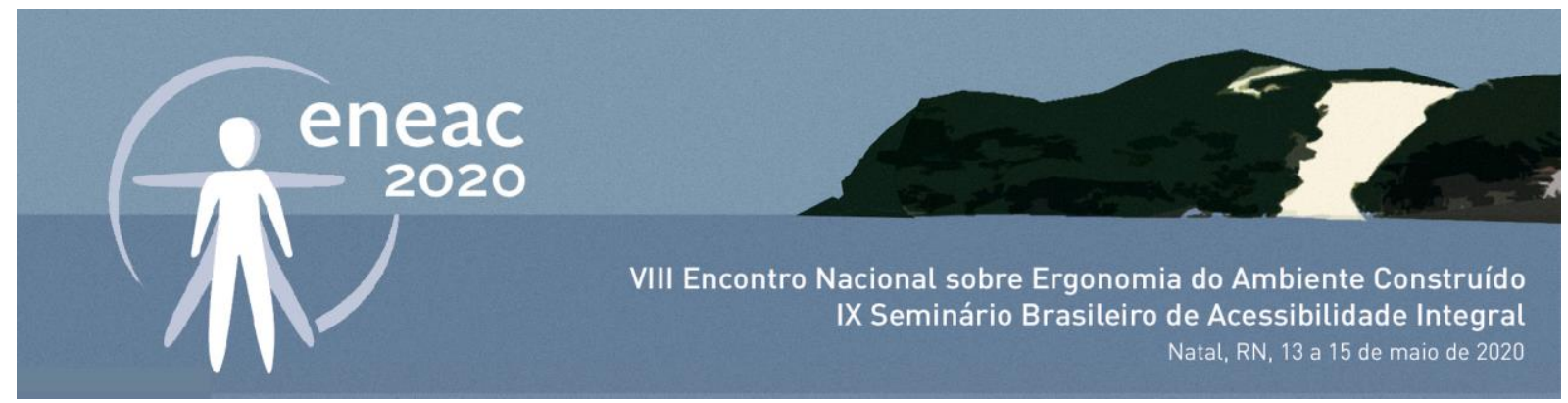

O projeto da Escola A é do Tipo PROINFANCIA B, com capacidade para atender até 224 crianças, em dois turnos (matutino e vespertino), ou 112 crianças em período integral. Foi considerada como ideal, que sua implantação ocorra em terreno retangular, com medidas de 40m x 70m, e declividade máxima de 3\% (Fundo Nacional de Desenvolvimento da Educação, 2013).

A planta baixa da escola A organiza-se em torno de um pátio central, e três blocos de ambientes de estudo/trabalho (ver Figura 2). O pátio torna-se uma centralidade, ou ponto de encontro da comunidade estudantil (ver Figura 1b). Observando a distribuição dos setores em planta baixa (ver Figura 3), há dois corredores lineares onde distribuem-se as salas de aula e laboratórios e duas circulações transversais menores. A largura de corredores e pátio é livre de barreiras, garantindo a acessibilidade. $O$ setor administrativo ocupa dois blocos, próximo ao acesso, mantendo assim, um funcionamento organizado, tanto para professores, como para visitantes. Essa setorização proporciona uma organização espacial, evitando que ruídos indesejados possam atrapalhar o andamento das aulas. $O$ setor administrativo é bem iluminado e tem visão para áreas externas.

Na Figura 3, demonstra-se um mapa da permanência dos usuários na escola A. Durante a visita exploratória, todas as crianças se encontram realizando várias atividades de aprendizagem utilizando os diversos ambientes. Foram registradas atividades ocorrendo em salas de aula, no quintal e no pátio.

Figura 3: Mapa da análise da permanência de usuários na escola A.

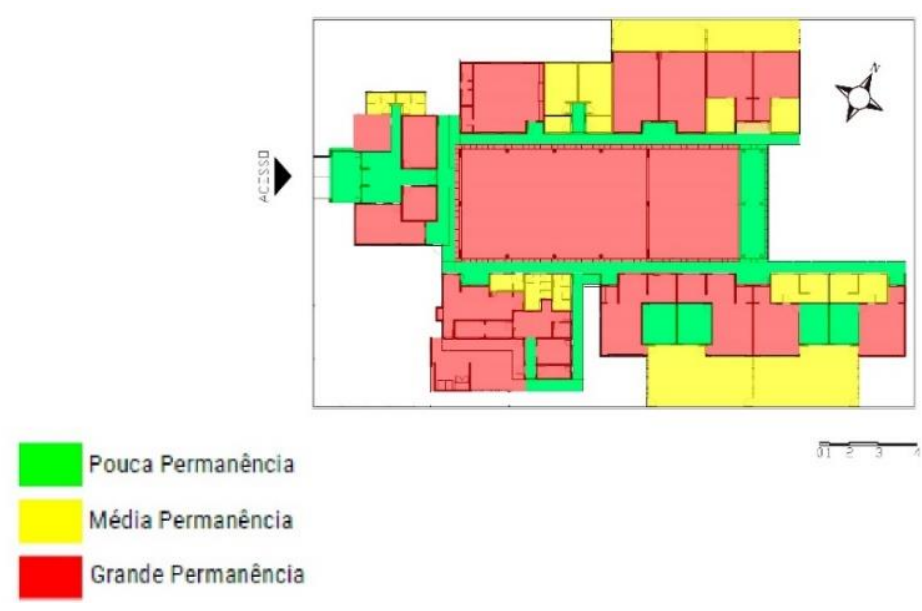

Fonte: as autoras.

Nos corredores, foi observado que eram utilizados apenas como espaços de curta permanência, exclusivo para circulação. A direção da escola permite que os estudantes personalizem os ambientes, com desenhos, pinturas e exposição de trabalhos.

O mobiliário utilizado nas salas é razoavelmente selecionado para a faixa etária dos estudantes, em algumas salas há mesas e cadeiras com dimensões adequadas a crianças acima de 8 anos, entretanto, para crianças menores, não há mobiliário específico. Existem muitos brinquedos e tapetes de borracha, estimulando a presença das crianças no chão. As cores utilizadas demonstram uma preocupação em torna os ambientes mais agradáveis para a criança. Os banheiros para os estudantes são adaptados ergonomicamente para as crianças: têm peças de louças adequadas, assim 


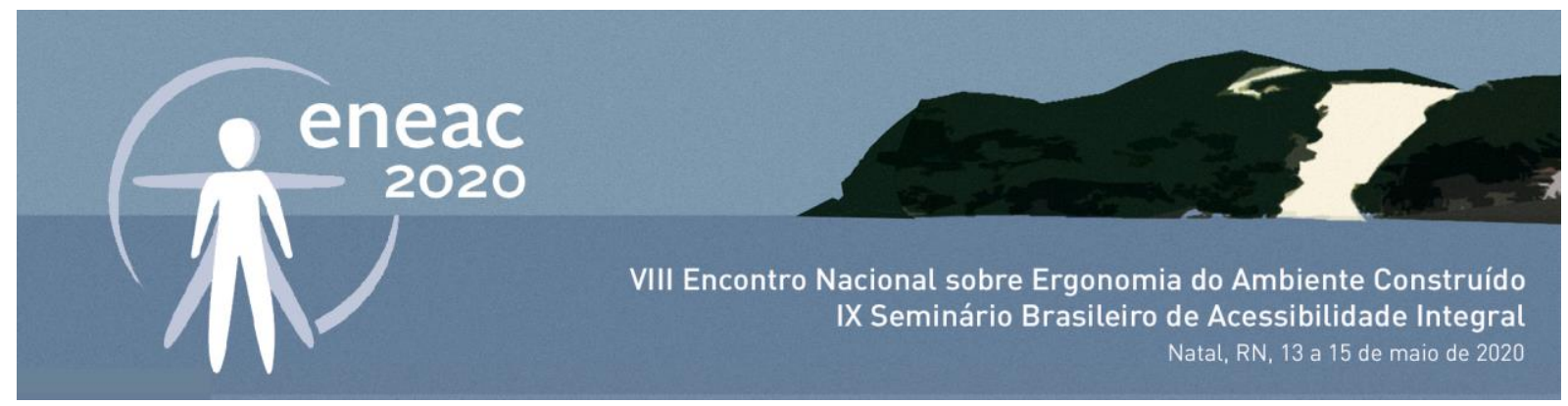

como a altura de pia e dos chuveiros (com base elevada do chão, permitindo uma melhor condição de trabalho para os cuidadores e proporcionando maior autonomia da criança em sua higiene pessoal.

Para análise das áreas internas úteis, dos ambientes escolares analisados foi utilizado como referência o Catálogo de Ambiente Especificações da Edificação Escolar (FDE, 2017). Foi possível analisar as condições dimensionais dos principais ambientes utilizados (sala de aula, pátio, sala de professores e banheiro dos estudantes). Segundo a FDE, a escola A (com 8 salas de aula e ensino fundamental inicial) se classifica como M2, e a tabela demonstra a análise dimensional do layout dos ambientes principais (Ver Tabela 1).

Tabela 1: Análise dimensional dos ambientes principais da escola A.

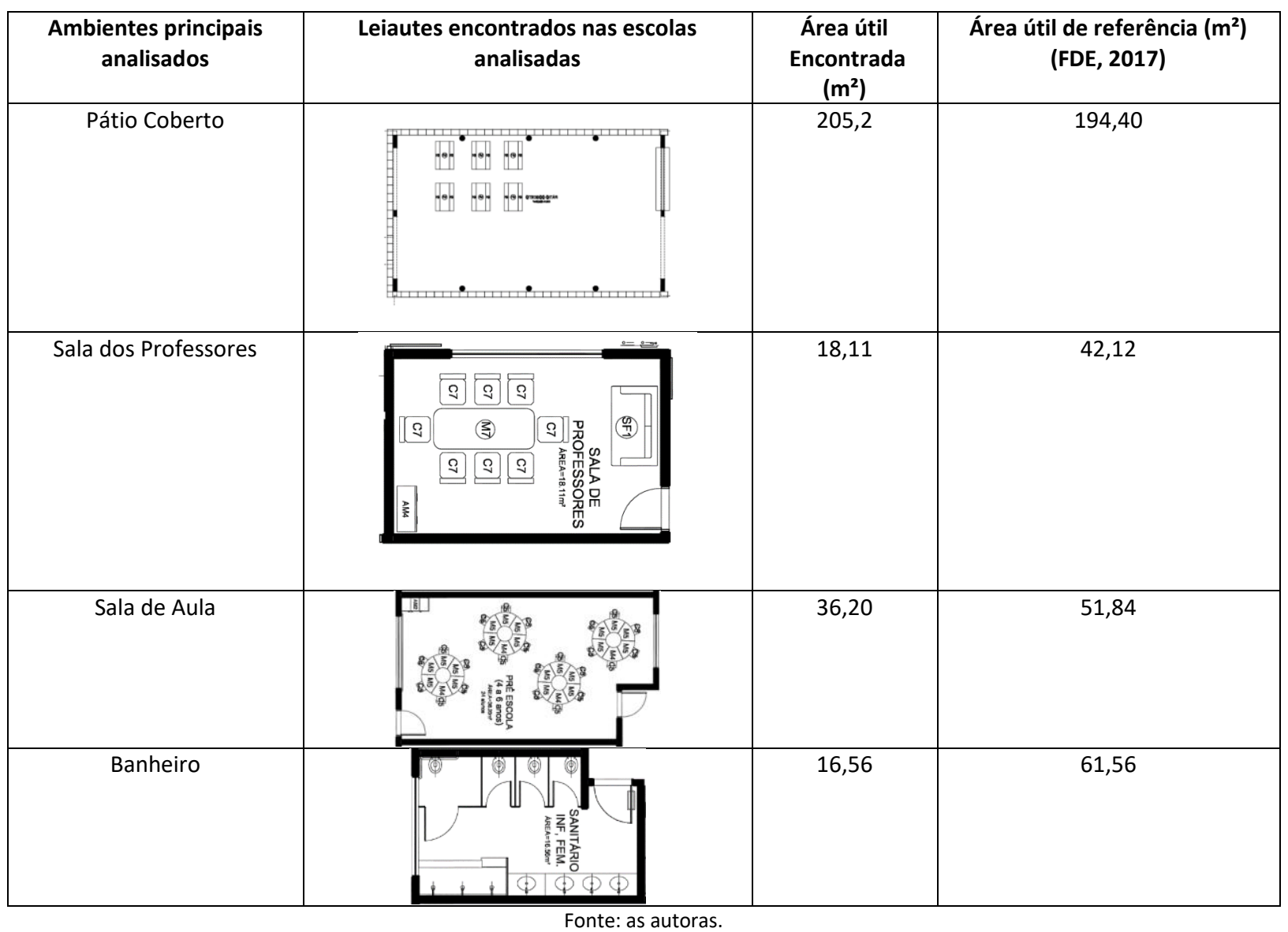

Percebe-se incompatibilidades dimensionais entre os ambientes da escola $\mathrm{A}$ e o catálogo de referência da FDE, exceto pelo pátio coberto, que oferece um dimensionamento maior que a referência. Os outros ambientes analisados apresentaram insuficiência dimensional, e conseguinte layout reduzido, com complicações em condições de acessibilidade, tamanho de aberturas, acomodação dos usuários em atividades de trabalho, de ensino e de aprendizagem. 


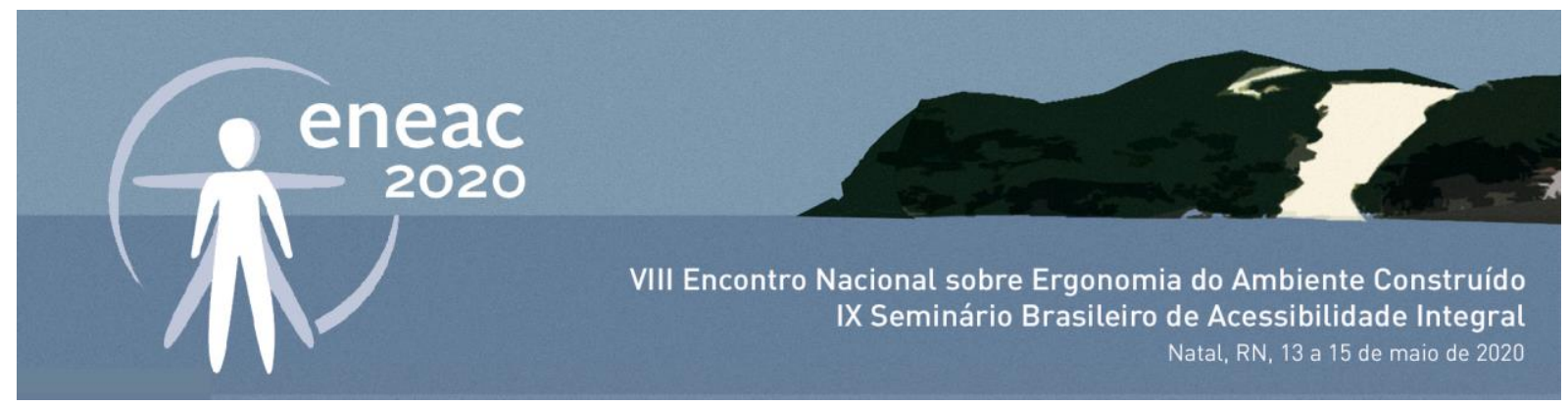

Em comparação com os layouts dos ambientes, o pátio coberto é o que tem menos mobiliário, são apenas mesas do refeitório e um grande banco localizado em espaço acessível, sem desníveis. $O$ banheiro dos estudantes apresenta box acessível, de acordo com as recomendações da NBR 9050 (ABNT, 2014). Os demais cabines sanitárias não seguem as recomendações da NBR 9050 (ABNT, 2014), sem espaço de circulação interna na cabine, que deveria ser mínimo de $60 \mathrm{~cm}$, ou com giro para fora.

A sala de aula tem um layout com mesa em grupos de 5 estudantes, possibilitando trabalhos em grupos, descentralizando o foco na lousa. As mesas e cadeiras tem o tamanho adequado para a faixa etária dos estudantes. As salas dos professores têm uma grande mesa para reunião e um pequeno sofá como área de descanso, embora o dimensionamento seja muito reduzido, menos que $50 \%$ da área recomendada pela FDE (2017).

\subsection{ESCOLA B - Escola Estadual Moreira e Silva (EEMS - CEPA):}

A escola foi criada no dia 18 de novembro de 1937, hoje está locada no Complexo Estudantil do CEPA. Esta escola é voltada para o ensino médio tem capacidade de mil oitocentos e vinte e um alunos, com faixa etária de 15 a 17 anos. A escola B distribui-se numa planta com três bloco lineares, e conta com biblioteca, laboratório de música, laboratório de ciências, ginásio, refeitório, cozinha, sala de vídeo, mini-auditório e sala para programa de rádio, além das vinte e duas salas de aulas disponíveis. A área construída é de cerca de $3 \mathrm{mil} \mathrm{m}^{2}$ (ver Figura 4).

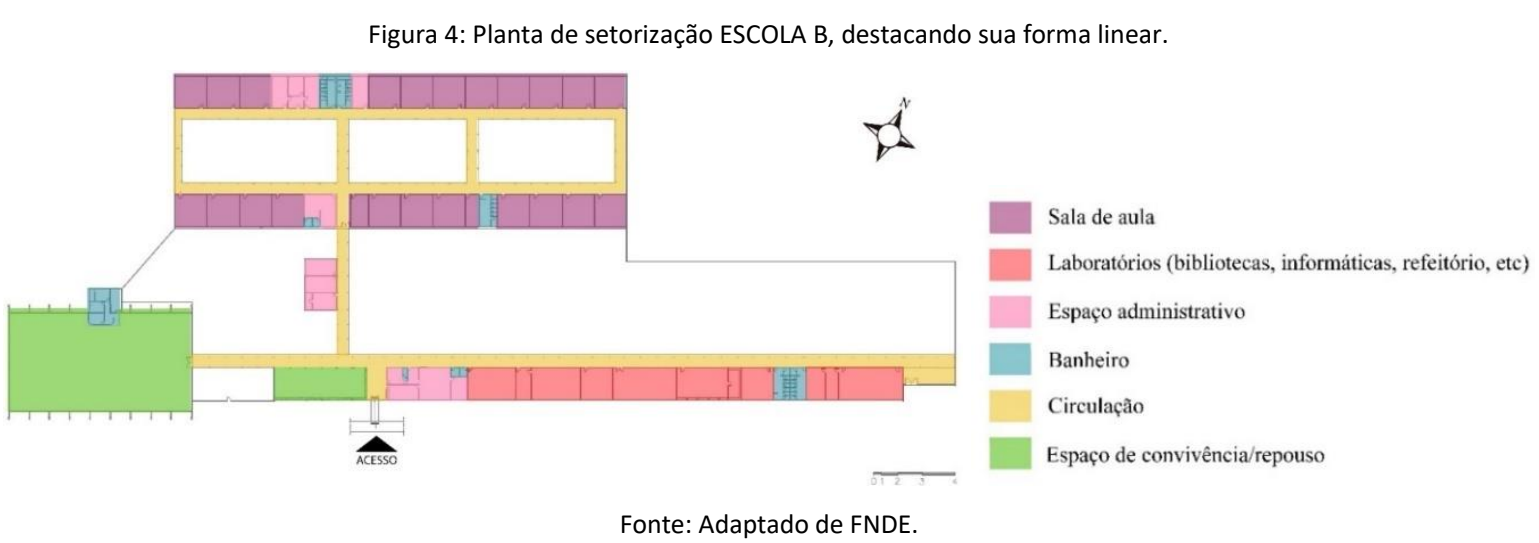

A planta baixa mostra uma linearidade em sua planta, com três grandes corredores longitudinais principais e cinco corredores transversais menores. Apenas um corredor dá acesso às salas de aula, estabelecendo um rígido controle sobre os alunos. Durante o horário de aulas, os alunos permanecem no bloco trancados por chaves e grades, não podendo acessar espaços de convivência ou quadra. As salas de aulas têm esquadrias de madeiras, com as medidas padronizadas, tanto para portas quanto para esquadrias. As janelas originais são do tipo venezianas, com o uso de cobogós para captar a ventilação e iluminação naturais, porém recentemente foram fechadas para instalação de aparelhos de com o uso do ar condicionado.

Em relação a metodologia de ensino e aprendizagem, adota-se o modelo tradicional, em que o professor permanece em aulas expositivas, de frente para a classe, e carteiras são organizadas 


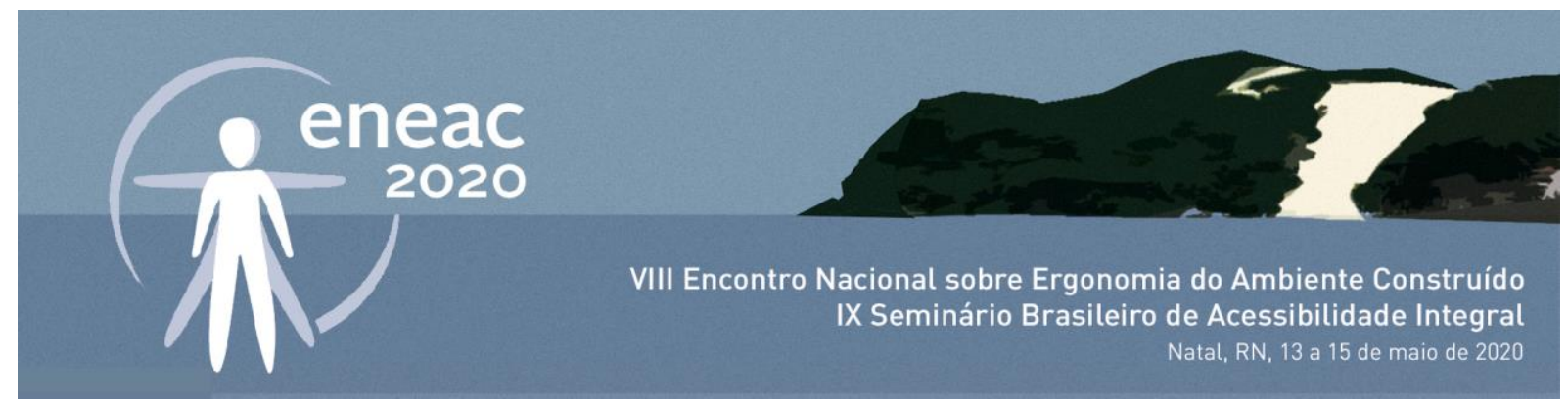

enfileiradas (Ver Figura 5a). O mobiliário das salas é leve, permitindo que haja reorganização de layouts diferentes, possibilitando a flexibilização, durante o uso.

Figura 5: Vista da sala de aula (a) e entrada para o pátio das salas (b)
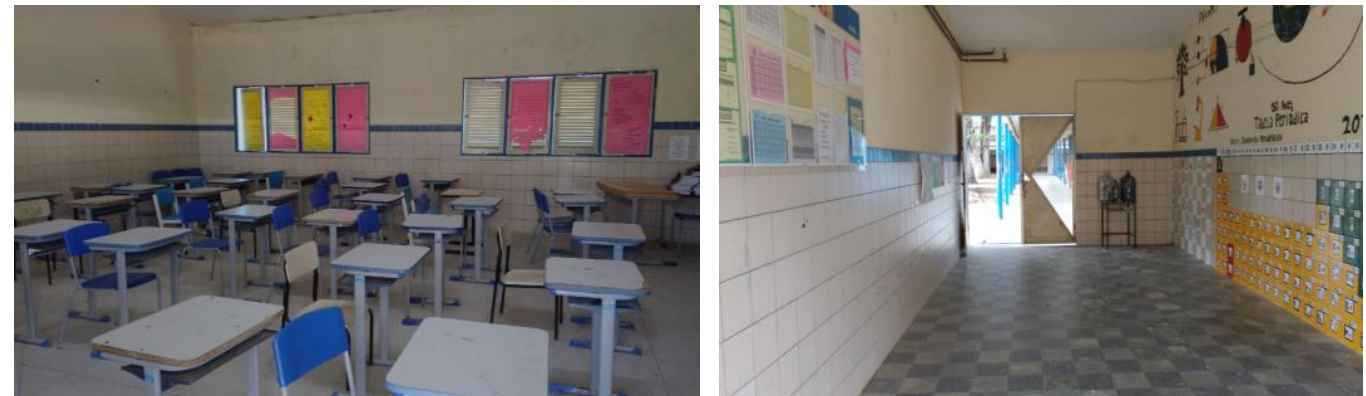

Fonte: As autoras.

A iluminação das salas de aulas não é suficiente para atividades de leitura, como mesmo com o uso de iluminação artificial, a sala permanece na penumbra. Uma das causas para a penumbra é o pé direito excessivamente alto, que dificulta a iluminação sobre a superfície da área de trabalho, como recomenda a NBR 8995-1 (2013). Para a verificação de inconformidades sobre o dimensionamento espacial, comparou-se os dados de áreas úteis dos principais ambientes utilizados, com o dimensionamento base do Catálogo de Ambiente Especificações da Edificação Escolar (FDE, 2017). Segundo a FDE (2017), esta escola é do tipo M12 (escola para ensino médio), por apresentar 24 salas de aula. A Tabela 02 (abaixo) mostra a análise dimensional.

Tabela 2: Análise dimensional de ambientes principais da Escola B.

\begin{tabular}{|c|c|c|c|}
\hline $\begin{array}{l}\text { Ambientes principais } \\
\text { analisados }\end{array}$ & $\begin{array}{l}\text { Layouts encontrados nas escolas } \\
\text { analisadas }\end{array}$ & $\begin{array}{c}\text { Área útil } \\
\text { Encontrada } \\
\left(\mathrm{m}^{2}\right)\end{array}$ & $\begin{array}{l}\text { Área útil de referência }\left(\mathrm{m}^{2}\right) \\
\text { (FDE, 2017) }\end{array}$ \\
\hline Pátio Coberto & 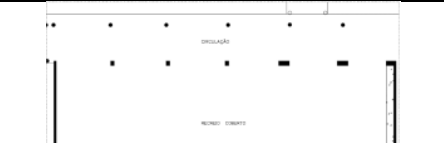 & 43,41 & 259,20 \\
\hline Sala dos Professores & & 15,20 & 68,04 \\
\hline Sala de Aula & 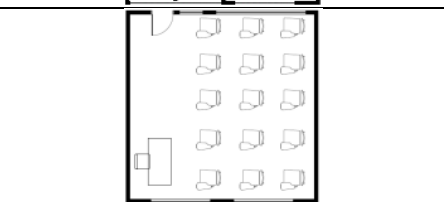 & 15,20 & 51,84 \\
\hline Banheiro & - & 7,5 & 78,57 \\
\hline
\end{tabular}




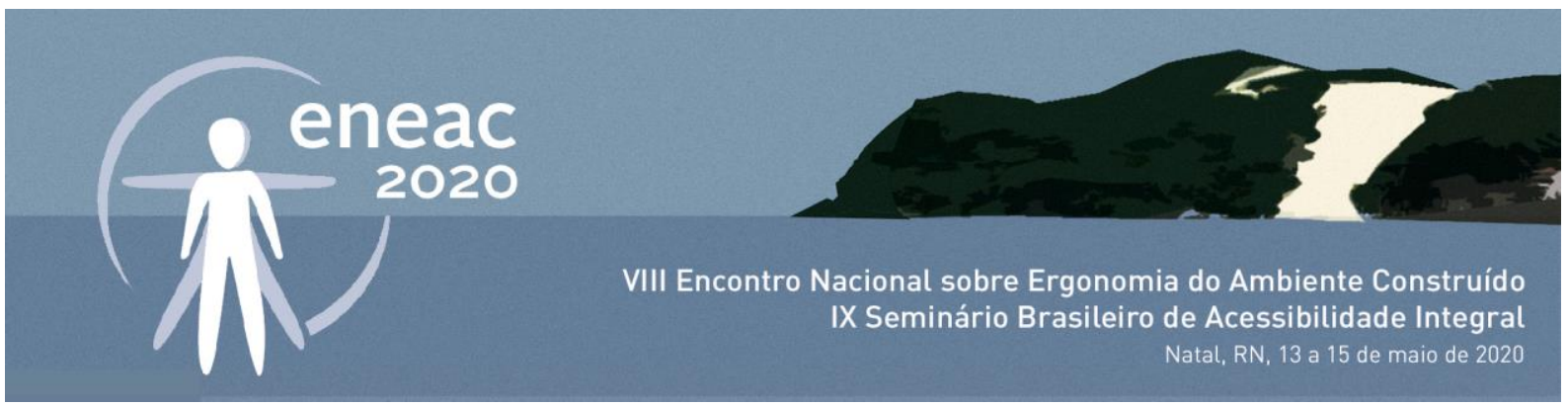

Fonte: as autoras.

A escola $B$ apresentou grandes incompatibilidades dimensionais, se comparada aos padrões da FDE (2017), pois o pátio coberto chega a ser $1 / 6$ da área recomendada e o banheiro chega a ser $1 / 10$ da área recomendada, assim como os demais ambientes de ensino e trabalho, que chegam a ser $1 / 4$ da área recomendada. Esse dimensionamento muito abaixo de padrões mínimos acarreta grande prejuízo aos usuários, pois impede a execução de atividades em condições de conforto e ergonomia, tanto para pessoas sem deficiências físicas, como para possíveis usuários que possam apresentar impedimentos de deslocamento temporários e permanentes.

O layout do pátio coberto da escola B segue o mesmo padrão da escola A, sem mobiliário, só existe um grande banco, isolado entre as paredes, tornando um espaço de pouco uso. A sala dos professores possui apenas duas mesas num espaço bem pequeno, onde existem ar-condicionado, cafeteria, sofá para descanso, mesa de reuniões/refeições. As salas de aula têm as carteiras articulada com mesa individuais, com a possibilidade de flexibilização de layout, porém a centralidade da aula é em atividades expositivas, personalizada no professor, a frente da turma. Os banheiros demonstram problemas graves de subdimensionamento, abertura de portas com giro para dentro, sem espaço de circulação mínima. Apenas a cabine acessível está corretamente projetada. A manutenção é inadequada, falta água e existem poucas aberturas para ventilação.

Analisando o desempenho global dos índices de conforto ambiental, percebe-se que o maior desconforto ocorre em relação a insolação indesejada, nas salas de aulas localizadas na extremidade da lateral esquerda. A insolação poente incide nas paredes, aquecendo-as no período da tarde. $O$ ginásio localiza-se nessa região e sofre parcialmente deste mesmo problema.

As salas de aula estão localizadas à noroeste. Apesar da proximidade com o poente, as aberturas estão bem localizadas conseguindo captar ventilação natural. Com o fechamento dos cobogós, a ventilação natural ficou prejudicada. As salas mais bem localizadas para melhor ventilação natural são localizadas no corredor inicial, onde estão os laboratórios (a sudeste). O setor administrativo encontra-se disperso pela escola, dificultando o trabalho interno e a legibilidade espacial, espacialmente para pais e visitantes.

Figura 6: Mapa do estudo de permanência da escola B.

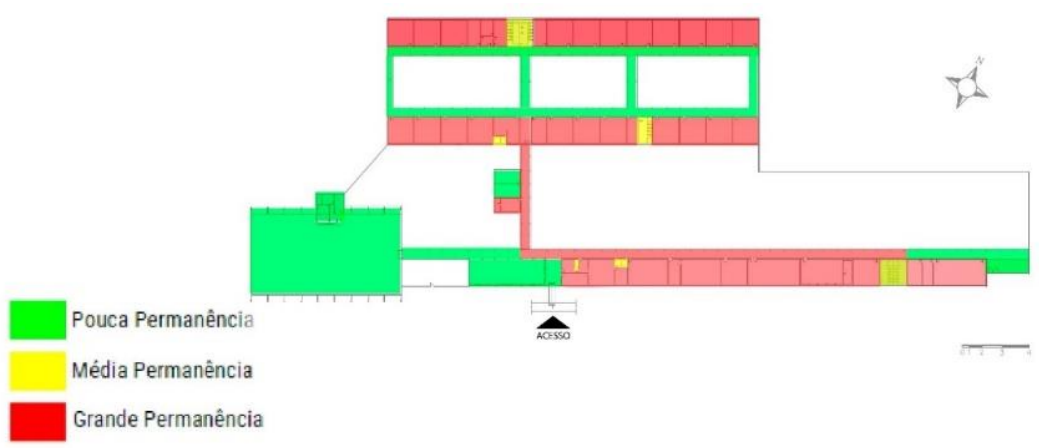

Fonte: as autoras.

A Figura 6 mostra a setorização dos ambientes da escola B, e as formas de permanência e uso dos ambientes. Um dos pontos de maior permanência é nas proximidades da porta de acesso principal 


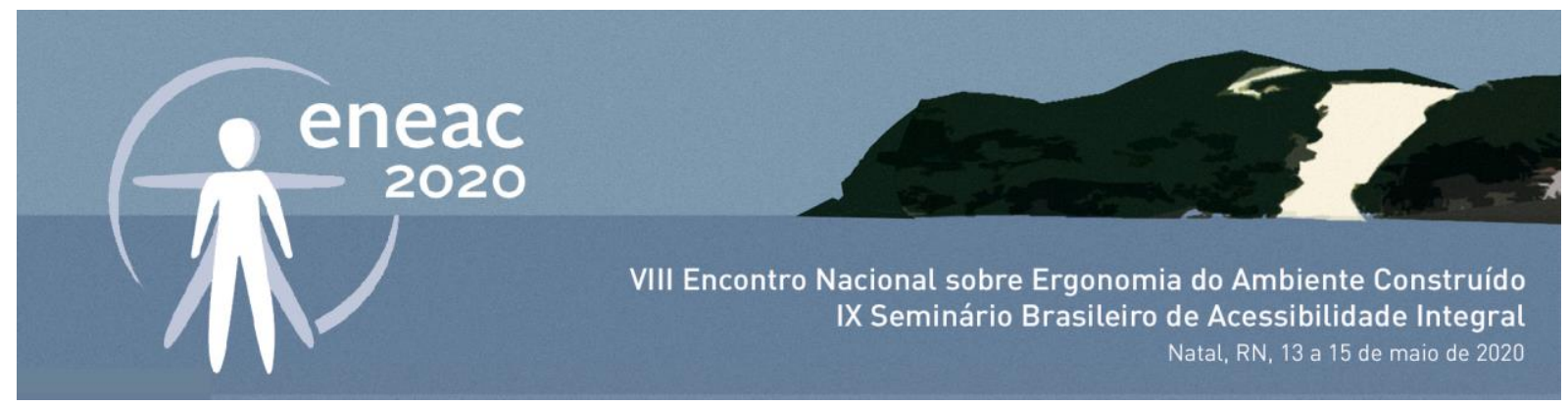

da escola. O controle de saída é rigoroso, por isso, os alunos esperam junto ao portão para serem liberados.

\subsection{ESCOLA C - Escola Estadual Princesa Isabel - EEPI/CEPA:}

A Escola C fica localizada no CEPA, Maceió, Alagoas, e apresenta a configuração espacial maior e mais complexa entre as três escolas analisadas. Durante a visita exploratória foi possível verificar a existência de dois grandes portões de acesso. O primeiro portão é gradeado, permitindo a visualização entre interior e exterior. No corredor entre os portões, há um acesso para secretária, evitando a entrada de pais e visitantes, a ambientes mais internos da escola.

O bloco principal de salas tem corredores largos e um pé direito duplo, entretanto a iluminação não é suficiente para os espaços de circulação, devido a forma do bloco ser em quadro fechado. Uma penumbra é notada e mesmo com a iluminação artificial, o nível de iluminação interna é inferior as recomendações normativas. Também em salas de aulas, apesar de haver janelas com vista para o exterior, a iluminação é insuficiente, e os índices observados não atingem a iluminância recomendada, entre 500 a 1000 lux, segundo a NBR 8995-1 (ABNT, 2013). Para a melhoria do desempenho lumínico deveria haver iluminação artificial de maior potencial luminoso.

O pátio central da escola $C$ é descoberto (Figura 7a), possui muita vegetação, com árvore frondosas, com iluminação natural abundante e uma ambiência bem agradável. O pátio central faz a conexão com os dois corredores longitudinais, porém não é um ponto de convergência para a circulação dos usuários, já que se encontra num dos encontros entre um bloco longitudinal e transversal.

Os deslocamentos principais são realizados em movimento de $U$, como pode ser visto na planta baixa de setorização (Figura 8). O pouco uso do pátio central pode ocorrer devido à falta de mobiliário para a permanência dos usuários, a incidência direta da luz solar, já que não há cobertura e a delimitação pouco convidativa da mureta que contorna o ambiente, segregando o pátio em relação aos corredores.

Figura 7: Vistas do pátio central (a) e corredor entre salas de aula (b).
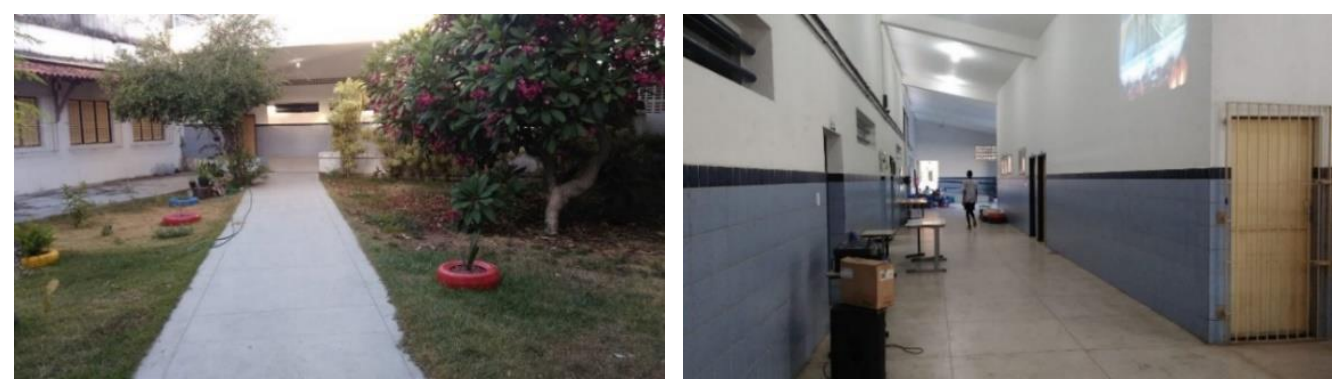

Fonte: As autoras.

O segundo bloco de salas tem novas 7 salas de aula e dá acesso ao ginásio esportivo. Essa parte nova é aberta e ampla, os corredores são claros, assim como o pátio coberto, apesar disso as salas tem iluminação insuficiente. A integração dos dois blocos acontece em vão livre e os alunos podem 


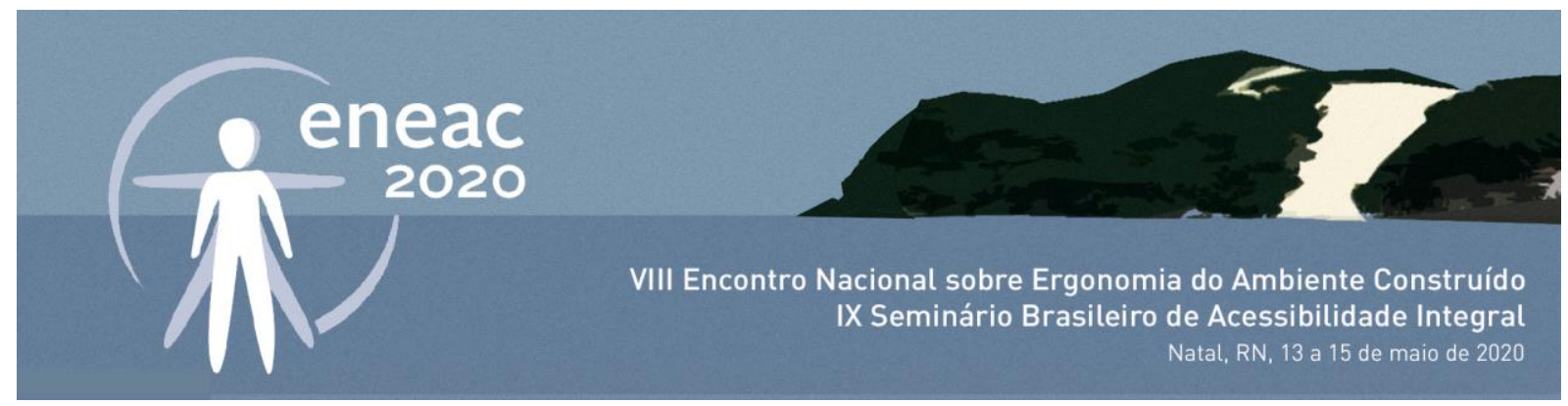

passar livremente entre os dois blocos. É possível perceber que a linguagem arquitetônica utilizada no bloco mais novo é de amplitude e iluminação proporcionada pelo formato em U (ver Figura 8).

Figura 8: Mapa de setorização da ESCOLA C.

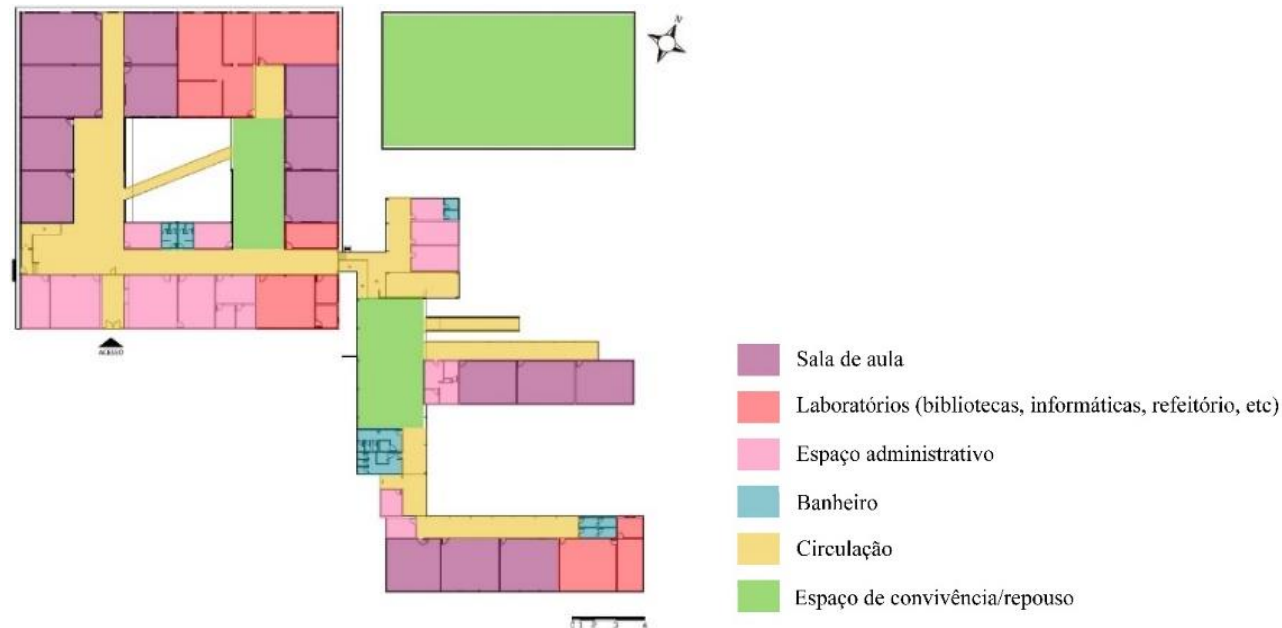

Fonte: Adaptado de FNDE.

Observa-se que o primeiro bloco tem uma abertura central, que ajuda na captação da ventilação natural, porém o setor administrativo tem uma orientação favorável à captação da ventilação e da insolação natural. A fachada do bloco administrativo tem boa ventilação e menos insolação durante o ano, as salas de aulas ficam desfavorecidas quanto à insolação nas fachadas noroeste e sudoeste. 0 segundo bloco é locado na fachada nordeste, captando a ventilação à leste, nordeste, sudeste e sul e o afastamento entre os blocos de sala causa melhoria na ventilação natural, sem criar um bloqueio dos ventos, para o primeiro bloco.

As esquadrias têm medidas padronizadas, executadas em madeira, com grades externas. As portas têm aberturas para o interior, e gradil com abertura para o exterior, demonstrando a política de controle da circulação no interior da escola. Para a análise das inconformidades dimensionais, utilizou-se o Catálogo de Ambiente Especificações da Edificação Escolar (FDE, 2017) para comparar com dados dimensionais obtidos in loco. Segundo a FDE, a escola C é do tipo M12, onde verifica-se a presença de 24 salas de aula, para o ensino médio. A tabela abaixo mostra a análise do dimensionamento dos ambientes de maior permanência na escola C (Ver Tabela 3).

Tabela 3: Análise do dimensionamento dos ambientes principais da escola C.

\begin{tabular}{|c|c|c|c|}
\hline $\begin{array}{c}\text { Ambientes principais } \\
\text { analisados }\end{array}$ & $\begin{array}{c}\text { Layouts encontrados nas escolas } \\
\text { analisadas }\end{array}$ & $\begin{array}{c}\text { Área útil } \\
\text { Encontrada } \\
\left(\mathbf{m}^{2}\right)\end{array}$ & $\begin{array}{c}\text { Área útil de referência }\left(\mathbf{m}^{2}\right) \\
\text { (FDE, 2017) }\end{array}$ \\
\hline Pátio Coberto & {[} & 135,14 & 259,20 \\
\hline Sala dos Professores & Acesso indisponível para elaborar layout & 51,10 & 68,04 \\
\hline
\end{tabular}



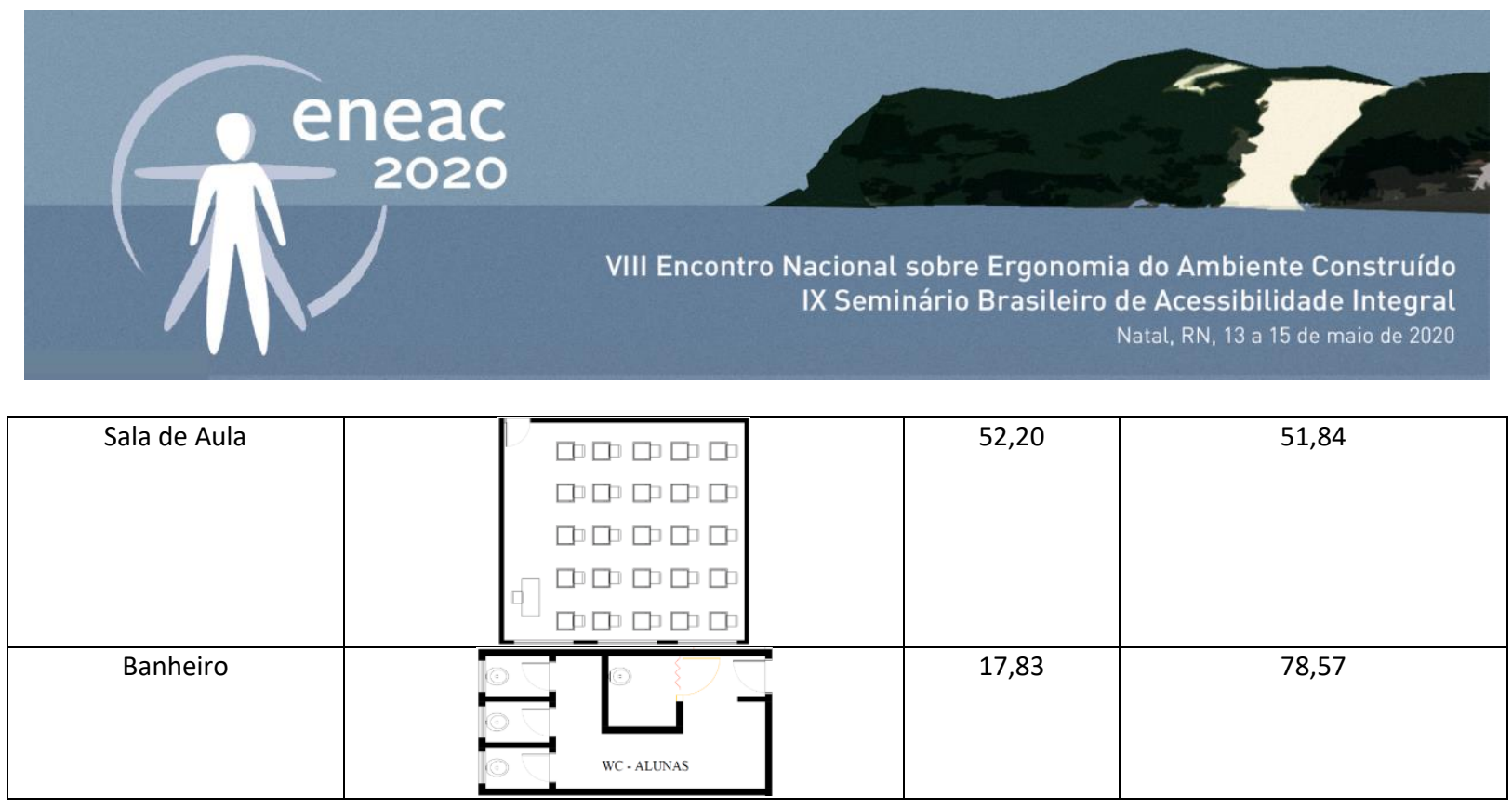

Fonte: as autoras.

A análise dimensional demonstrou incompatibilidades ao tomar como referência aos padrões da FDE (2017). Assim como nas escolas anteriormente analisadas, a maioria dos ambientes apresentou diferenças dimensionais, especialmente na sala de professores e nas salas de aula. A área útil do pátio coberto chega a ser 50\% da área recomendada pela FDE (2017) e o banheiro chega a atingir $25 \%$ da área recomendada como tamanho ideal, prejudicando a circulação e o conforto dos usuários. O layout do pátio coberto apresenta nenhum mobiliário, impedindo a permanência dos estudantes em condições de conforto ergonômico e psicológico. Não foi permitido entrar em salas administrativas para realizar a análise de layout.

Em relação aos layouts de salas de aula, o padrão de mobiliário é de carteiras com braço, em fileiras lineares, no qual o foco é a posição do professor, em atividade expositiva, diante da lousa. O layout é passível de flexibilização, já que o mobiliário é leve (ver Figura 9). Os banheiros da escola C apresentaram os mesmos problemas de pouca circulação interna, problemas da abertura das portas, também encontrados nas escolas $A$ e $B$, sendo que a cabine acessível está adequada, de acordo com a NBR 9050 (ABNT, 2014). Analisa-se os espaços de maior permanência, e observa-se que os usuários passam maior parte do tempo nas salas de aula ou nos laboratórios. As salas de aulas encontravamse abertas e com alguns alunos dentro delas, mesmo fora de horário de aula. Os corredores são apenas espaços de circulação, não havendo mobiliário que propicie a permanência.

Figura 9: Classificação de permanência da escola C.

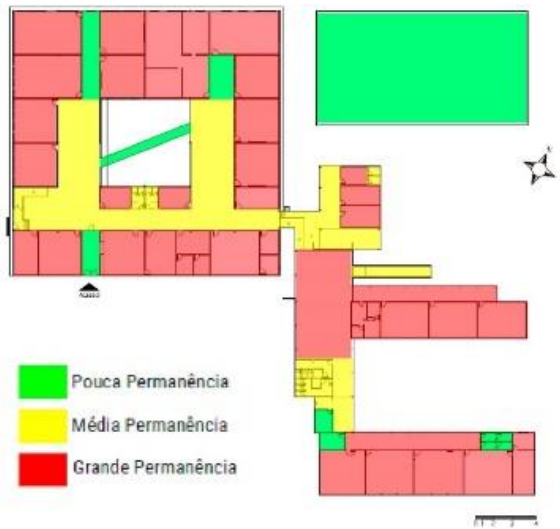

Fonte: As autoras. 


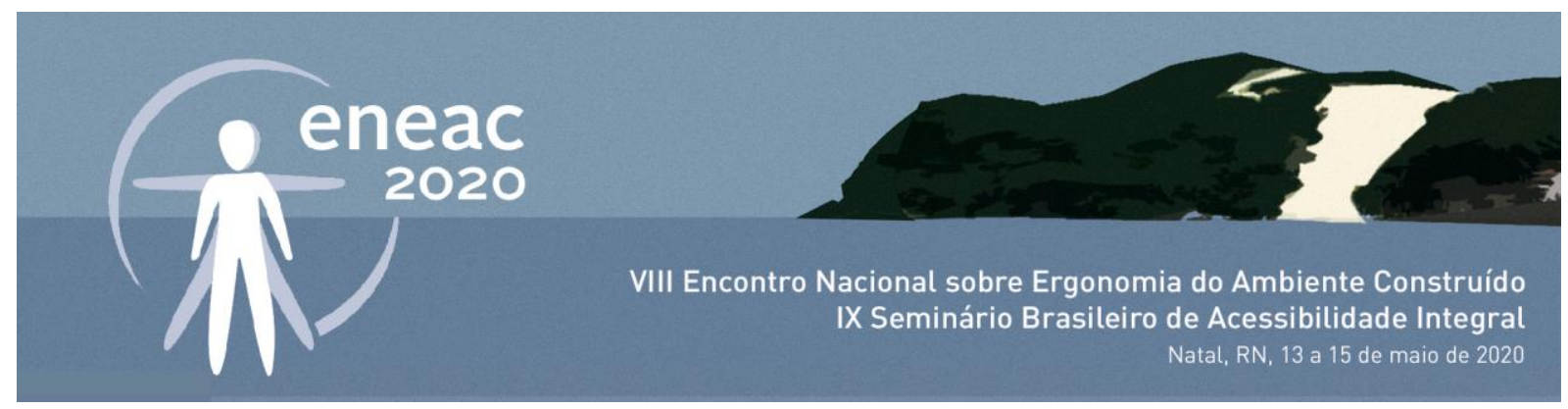

\section{CONSIDERAÇÕES FINAIS}

As análises realizadas mostraram que a configuração espacial das escolas públicas em Alagoas ainda segue padrões convencionais, mesmo considerando que está em curso a implantação de modelos de educação no formato integral, uso de novas tecnologias educacionais. As plantas baixas seguem utilizando formas em L, ou em linhas paralelas, em longo corredores de salas. Mesmo para padrões construtivos básicos, foram encontradas inconsistências dimensionais que implicam em sérios desconfortos, desde dimensionais e até mesmo de percepção, que afetam o bem-estar geral dos usuários, o rendimento escolar, o relaxamento e o pertencimento que deve haver para criar condições propícias à aprendizagem do século XXI, e a colaboração mútua.

Este estudo aponta a necessidade de realizarem-se maiores aprofundamentos sobre o tema da arquitetura escolar em Alagoas, a fim de conhecer e caracterizar os usuários e seus elementos formadores, sociais e culturais, que influenciam na educação formal. Espaços de educação também são agentes educadores que definem comportamentos sociais e de ação cidadã, contribuindo para o bem-estar geral de comunidades e populações, desde a formação de crianças e jovens.

\section{REFERÊNCIAS}

ALCANTARA, P. G. de F. Análise de parâmetros de condições acústicas nas escolas municipais da cidade de João Pessoa. In: ENEAC - ENCONTRO NACIONAL DE ERGONOMIA DO AMBIENTE CONSTRUÍDO, 3., 2011, João Pessoa. Anais [...]. João Pessoa: UFPB, 2011, p. 1-12.

ARANHA, Maria Lúcia de Arruda. História da Educação. 2ª̣ed. São Paulo: Moderna, 1996.

ASSOCIAÇÃO BRASILEIRA DE NORMAS TÉCNICAS - ABNT. NBR 10151: Acústica - Avaliação do ruído em áreas habitadas, visando o conforto da comunidade - Procedimento. Rio de Janeiro: ABNT, 2000.

ASSOCIAÇÃO BRASILEIRA DE NORMAS TÉCNICAS - ABNT. NBR 10152: Níveis de ruídos para conforto acústico. Rio de Janeiro: ABNT, 1987.

ASSOCIAÇÃO BRASILEIRA DE NORMAS TÉCNICAS - ABNT. NBR 15220: Desempenho térmico de edificações - Parte 1, 2 e 3. Rio de Janeiro: ABNT, 2003.

ASSOCIAÇÃO BRASILEIRA DE NORMAS TÉCNICAS - ABNT. NBR 9050: Acessibilidade e edificações, mobiliário, espaços e equipamentos urbanos. 3a edição. Rio de Janeiro: ABNT, 2015.

ASSOCIAÇÃO BRASILEIRA DE NORMAS TÉCNICAS. NBR ISO/CIE 8995-1: iluminação de ambientes de trabalho. Parte 1: interior. Rio de Janeiro: ABNT, 2013, 46p.

BERTOLOTTI, D. Iluminação natural em projetos de escolas: uma proposta de metodologia para melhorar a qualidade da iluminação e conservar a energia. 2007. Dissertação (Mestrado em Arquitetura e Urbanismo) - Faculdade de Arquitetura e Urbanismo, Universidade de São Paulo, São Paulo, 2007.

CHAN, T. C. e RICHARDSON, M. D. Ins and outs of school facility management: More than bricks and mortar. Lanham, MD: Scarecrow Education. 2005.

DELIBERADOR, M. S. O processo de projeto de d e arquitetura escolar no Estado de São Paulo: Caracterização e possibilidades de intervenção. (Dissertação de Mestrado), Universidade Estadual de Campinas - UNICAMP, 2010.

FUNDAÇÃO PARA O DESENVOLVIMENTO DA EDUCAÇÃO - FDE. Produtos Técnicos - Programas Arquitetônicos dezembro 2017. 2017b. Disponível em: https://produtostecnicos:fde:sp:gov:br/Pages/CatalogosTecnicos/ Catálogos/Ambientes/Programas_Arquitetonicos_dezembro_17:pdf. Acesso em: 12 jan. 2020.

FNDE. Projeto Tipo B. 2013. Disponível em: https://www:fnde:gov:br/index:php/programas/proinfancia/eixos-deatuacao/projetos-arquitetonicos-paraconstrucao/item/4816-tipo-b. Acesso em: 18 Dez 2019. 


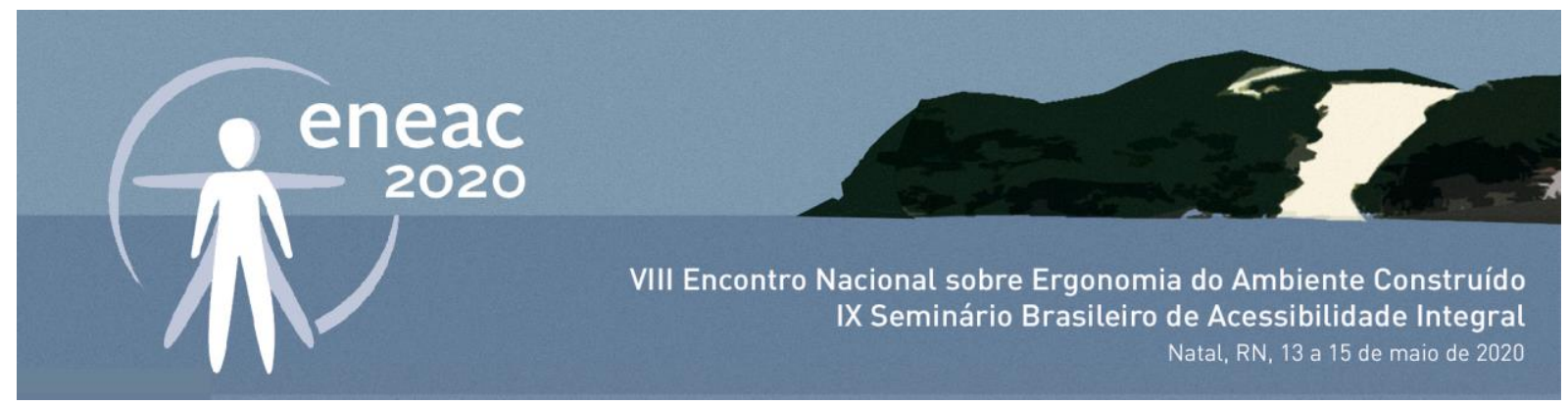

GUIDALLI, C. R. R.; BINS ELY, V. H. M. Conforto visual nas salas de aula de universidades. In: ENCONTRO NACIONAL DE ERGONOMIA DO AMBIENTE CONSTRUÍDO, 6., 2013, Florianópolis. Anais [...]. Florianópolis: UFSC, 2013.

GURGEL, M. Design Passivo, baixo consumo energético. Guia para conhecer, entender e aplicar os princípios do Design Passivo em residências. São Paulo: Ed. Senac São Paulo, 2012.

INSTITUTO NACIONAL DE ESTUDOS E PESQUISAS EDUCACIONAIS ANÍSIO TEIXEIRA. Censo Escolar 2017: notas estatísticas. Brasília: INEP/MEC, 2018. Disponível em:

http://download.inep.gov.br/educacao_basica/censo_escolar/notas_estatisticas/2018/notas_estatisticas_Censo_Escolar_2 017.pdf. Acesso em: 20 out. 2018.

KAUP, M. L.; KIM, H.; DUDEK, M. Planning to Learn: The Role of Interior Design in Educational Settings. International Journal of Design for Learning, v. 4, n. 2, p. 41-55, 2013.

KOWALTOSKI, D. C. C. K; BORGES FILHO, F.; LABAKI, L. C.; RUSCHEL, R. C.; BERTOLI, S. R.; PINA, S. A. M. G. Melhoria do conforto ambiental em edificações escolares estaduais de Campinas - SP. Relatório (Pesquisa Científica) Universidade de Campinas - Unicamp. Campinas, 2001

KOWALTOSKI, D. C. C. K. Arquitetura Escolar, o projeto do ambiente de ensino. São Paulo: Ed: Oficina de textos, 2011.

LAMBERTS, R.; DUTRA, L. PEREIRA, F. O. R. Eficiência energética na arquitetura. 3ą. Ed. Rio de Janeiro: PROCEL, 2014. p. 151- 168. Disponível em: http://www.labeee.ufsc.br/sites/default/files/apostilas/eficiencia_energetica_na_arquitetura.pdf. Acesso em 15 Dez 2019.

MORAN, J. Educação Híbrida, um conceito-chave para educação hoje. In: BACICH, L.; TANZI NETO, A.; TREVISANI, F. M. (orgs.) Ensino Híbrido: Personalização e Tecnologia na Educação. São Paulo: Penso, 2015. 252p. 23-42pp.

SANTIAGO, Z. M. P. Arquitetura e instrução pública: A reforma de 1922, concepção de espaços arquitetônicos e formação dos primeiros grupos escolares no Ceará. Coleção de História da Educação. Edições UFC, Fortaleza, 2017, 368p.

SARMENTO, T. F. C. S.; VILLAROUCO, V.; GOMES, A. S. Arranjos espaciais e especificações técnicas para ambientes de aprendizagem adequados a práticas educacionais com Blended Learning. Ambiente Construído, 2020, v. 20, n. 1, p. $365-$ 390, jan./mar. 2020.

SARMENTO, T. F. C. S.; GOMES, A. S. Design do ambiente escolar para aprendizagem criativa. Série Professor Criativo. Pipa Comunicações, Recife, 2019.

SCHMID, A. L. A ideia de Conforto: Reflexões sobre o ambiente construído. 1. Ed. Curitiba: Pacto Ambiental, 2005.

SOUZA, L. N. Arquitetura escolar, parâmetros de projeto e modalidades de aprendizagem. (Dissertação) - Mestrado em Arquitetura e Urbanismo, Universidade Estadual de Campinas. Campinas: Unicamp, 2018. 